\title{
Social Desirability and Affect: Linking Domains of Content
}

\author{
Leif-Eric Eichenbrenner \\ Department of Psychology, College of Healthcare Sciences \\ James Cook University \\ Edward Helmes \\ Department of Psychology, College of Healthcare Sciences \\ James Cook University
}

\begin{abstract}
Emotions influence decision making as do more general personal and social values. Conflict between these factors may result in increased processing time in order to select a single response to self-report personality measures. Given the broad influence of social desirability on test responding, the current study assessed affective reactions to adjectives with known social desirability evaluations for the purpose of evaluating whether the affect experienced by an evaluator is related to the social desirability of the stimuli. Twenty-nine university undergraduates responded with either approach or avoidance to a series of adjectives used in personality assessment with the MyersBriggs Type Indicator. Words with higher social desirability values received more positive affective evaluations and had faster response times, suggesting a link between affect and social desirability. Discussion of the findings relates to current theoretical models on social desirability and affect.
\end{abstract}

Keywords: affect; social desirability; decision-making; evaluation; Myers-Briggs Type Indicator

\section{SOCIAL DESIRABILITY AND AFFECT: LINKING DOMAINS OF CONTENT}

Decision making on any particular matter is influenced both by the individual factors involved (e. g., personal preferences, past experiences) and by relevant societal values (e. g., general evaluation or social desirability). According to Slovic, Finucane, Peters and MacGregor [1], affect refers to the specific quality of goodness or badness of the emotion arising from experiencing a stimulus. This is not to say that affect is a quality that resides in the stimulus, but rather that people rapidly, and possibly automatically, evaluate their environments and experience a sense of the goodness or badness as an emotional response to specific stimuli. Cacioppo, Berntson and Gardner [2] argue that these affective judgements are performed by a specialized mental process distinct from that responsible for identifying the stimulus, and may serve an adaptive function as the basic motivation for approach/avoidance behaviors [3]. For the purposes of this study, affect is defined as "the set of operations necessary to decide if one's initial reaction to a stimulus is positive or negative."

Social desirability is commonly defined as "the set of operations necessary to assign a numerical social desirability value to an item" [4, p.1]. In the past, researchers have assessed this construct by asking people if a particular attribute is desired by a specific group of people (e. g, peers), by society in general, or by asking them if they would find the attribute desirable in others. This process is distinct from faking, or the attempt to present a false image [5]. A key difference between affect and social desirability judgments is that affect refers to how positively or negatively an observer reacts to a stimulus. 
Two theoretical frameworks make distinct predictions about how a relationship between social desirability and affect might operate. Studies of adjectives from the English lexicon have replicated a single factor that is generally labelled as "evaluation" or "social desirability" $[3,6]$. Another model emphasizes personal qualities of the person responding. Paulhus [7] conceptualizes socially desirable responding as a function of the internal processes of impression management and self-deception. Both processes imply increased response time in cases in which the item has highly salient social desirability [7. 8]. The relationship between affect and social desirability may be one in which the perceived social desirability of a stimulus causes a person to either experience positive affect in responding or to respond in the direction associated with the rated social desirability. Under this model, a curvilinear relationship is expected between the social desirability of items and reaction time, with the slowest reactions occurring at either end of the social desirability continuum.

Stenberg, Wiking and Dahl [9] showed that words which generate positive affect are evaluated more rapidly than words which generate negative affect. When the affective response is congruent with the evaluative properties of the item, response speeds should be faster than when the two are incongruent [10]. Cacioppo et al. [2] argue in favor of the idea that the normal resting baseline for the affective system is mildly positive rather than neutral. This is an important adaptive feature which motivates curiosity towards novel stimuli, which in turn leads to exploratory behaviors. Cacioppo et al. [2] also argue that most experimental conditions produce mild positive affect. This operates in tandem with a negativity bias. Stimuli or items that generate negative affect attract people's attention and hold it because it may present a threat to them that must be monitored. While people tend to move towards positive affect, when they do experience negative affect they attend to it for longer. Thus, the positivity bias is not a result of faster processing for stimuli which generate positive affect, but rather a result of relatively longer, more cognitively intense processing of stimuli that generate negative affect. Both forms of socially desirable responding (self-deception and impression management [7]) increase the amount of processing required for items both high and low in social-desirability. It is therefore possible that the evaluative context for words may be coming from the study itself or a pervasive general tendency towards positive affect in the absence of negative affect.

While a link between affective responses to evaluative items is predictable, the nature of that link is less predictable across the range of socially desirable or evaluative content. The purpose of the current study is to evaluate whether there is a positive relationship between peoples' judgments of how socially desirable a word is and the positive or negative feelings generated by the word. The neutral conditions under which social desirability and affect data were collected should result in a mild positive affect. This provides the evaluative context which influences subsequent judgments.

Words which are more socially desirable are expected to lead to more positive ratings of affect, so it would be expected that these variables would be correlated. It would also be expected that words which produce positive affect would be evaluated faster than words which produce negative affect, because people would attend to negative words for longer and expend more cognitive resources evaluating them.

\section{Participants}

\section{METHOD}

Twenty-nine first and second year psychology students (24 females) from James Cook University, Australia participated. The age of the participants ranged from 17 to 47 years with 
a mean of 22.4 years (SD = 7.60). Participants received credit towards their studies for participation. This sample size was based on calculating power for detecting a correlation of 0.5 with a probability of .80 and Type 1 error rate of .05.

\section{Procedure}

After receiving instructions and providing informed consent, participants were seated at a computer. They were instructed that the computer would display a series of words, which they would evaluate in terms of the initial feelings they experienced in the presence of the word. If they evaluated the word positively, they should pull the joystick towards themselves, and if they evaluated the word negatively, they should push the joystick away from themselves. Participants were told to "try not to think about it too much, and just give your first, initial emotional reaction". Participants were instructed to sit in such a way that their arm was at a right angle when the joystick was in the neutral position. This served to ensure all participants had to make a significant movement in order to respond, and to standardize that movement between participants. Response speed was repeatedly emphasized in the instructions (i.e., "Speed is a factor in this, so please respond as quickly as possible") as was an individual affective response (i. e., "this is about your personal emotional response to the word"). The computer recorded responses and response speeds, after which the experimenter answered any questions the participants had, gave them a feedback sheet with relevant contact information, and thanked them for their participation.

\section{Materials}

The equipment at each of the two test stations included a joystick, IBM compatible PC, Superlab software, and software to enable Superlab to receive input from the joystick. The joysticks were Logitech Wingman USB joysticks featuring Microsoft-compatible human interface device controllers designed for use with video games. The joysticks were connected to the PCs and Joystick 2 Mouse 3.20 software was used to convert all forward movements of the joystick into simulated keyboard input of the letter $\mathrm{N}$, and all backwards movements of the joystick into simulated keyboard input of the letter P. All other buttons and movements on the joystick were set to be ignored in the software. Superlab 4.0 software was used to display stimulus words and record which of the two simulated keyboard letters was pressed ( $\mathrm{N}$ or $\mathrm{P}$ ) as well as the amount of time (in milliseconds) that passed between presentation of a stimulus and the participant making a response. The words displayed on the screen and evaluated by participants were those used in part 2 of the Myers-Briggs Type Indicator (MBTI), a nonclinical personality inventory. Part 2 consists of 45 pairs of words in which the test-taker under normal conditions selects one of the two words as more descriptive of them [11]. In this study the words were displayed individually, with presentation order randomized for each participant.

\section{Measures}

Helmes, Harris, and Fraboni [12] provided ratings of the words' social desirability based upon the Wiggins [4] definition. These social desirability evaluations were used because they were obtained recently. Mean affect response type across participants was used as a measure of affect direction (positive or negative) and affect strength (frequency of positive responses across participants) for each stimulus word. The number of positive responses for each stimulus word was counted. Because response type is a binary variable, and all responses that are not positive must be negative, the decision to use positive responses was arbitrary. Mean affect response speed was used as an additional measure of affect strength. 


\section{Results}

Response speed ( $\mathrm{M}=856.5$ msec., $\mathrm{SD}=244.8, \mathrm{~N}=29$ ) was found to be acceptably normally distributed (Kurtosis $=-.61, \mathrm{SE}=.85$, Skewness $=.50, \mathrm{SE}=.43$ ) and free from outliers. Visual examination of a bivariate plot of the relationship between social desirability and affect response speed did not suggest the type of curvilinear relationship that would be expected from items with highly salient social desirability producing slower responses. Data for affect response type (Kurtosis $=2.13, \mathrm{SE}=.50$, Skewness $=1.48, \mathrm{SE}=.25$ ) and affect response speed (Kurtosis $=.43, \mathrm{SE}=.53$, Skewness $=.82, \mathrm{SE}=.25$ ) were deemed to violate the normality assumption required for Pearson's correlation, so these variables were correlated using Spearman's rank order correlation. A correlation between social desirability judgments for stimuli words $(\mathrm{M}=6.2, \mathrm{SD}=.6, \mathrm{~N}=90)$ and response time $(\mathrm{M}=856.5, \mathrm{SD}=126.14, \mathrm{~N}=90)$ was highly significant, $\mathrm{r}(88 \mathrm{df})=.45, \mathrm{p}<.01$. The correlation between positive responses $(\mathrm{M}=22.4$, $\mathrm{SD}=4.86, \mathrm{~N}=90$ ) and response time was also highly significant, $\mathrm{r}(88 \mathrm{df})=-.68, \mathrm{p}<.01$, as was the correlation between social desirability and positive responses, $r(88 \mathrm{df})=.59, \mathrm{p}<.01$. Word length was correlated with response speed in order to determine if speed of responding was influenced by differences in the time required to process the words alone. The correlation between response time and number of letters in stimulus words $(\mathrm{M}=7.4, \mathrm{SD}=2.21, \mathrm{~N}=90)$ was not significant, $r(88 \mathrm{df})=.18$. Table 1 shows a complete list of the 90 words used alongside mean social-desirability ratings, reaction time in milliseconds, and the total number of positive evaluations made. 
Table 1. Descriptive statistics for social desirability, positive responses, and reaction times for adjectives from the Myers-Briggs Type Indicator

\begin{tabular}{|c|c|c|c|c|c|c|c|}
\hline Word & \begin{tabular}{|c|} 
Mean \\
SD \\
Rating
\end{tabular} & $\begin{array}{l}\text { Reaction } \\
\text { Time } \\
\text { (MS) }\end{array}$ & $\begin{array}{c}\text { Positive } \\
\text { Responses } \\
\text { (number) }\end{array}$ & Word & $\begin{array}{c}\text { Mean SD } \\
\text { Rating }\end{array}$ & \begin{tabular}{|c|} 
Mean \\
Reaction \\
Time (MS) \\
\end{tabular} & $\begin{array}{c}\text { Positive } \\
\text { Responses } \\
\text { (number) }\end{array}$ \\
\hline Scheduled & 7.231 & 811.655 & 22 & Hard & 5.4 & 876.483 & 8 \\
\hline Unplanned & 4.654 & 1081.621 & 6 & Sensible & 6.52 & 712.379 & 27 \\
\hline Gentle & 6.731 & 674.379 & 26 & Fascinating & 6.84 & 768.276 & 27 \\
\hline Firm & 5.692 & 970.276 & 17 & Forgive & 6.92 & 743.207 & 26 \\
\hline Facts & 6.654 & 695.172 & 24 & Tolerate & 6.52 & 981.241 & 19 \\
\hline Ideas & 6.538 & 798.379 & 29 & Production & 6.2 & 867.966 & 23 \\
\hline Thinking & 6.346 & 744.862 & 24 & Design & 6.44 & 755.069 & 26 \\
\hline Feeling & 6.5 & 699.069 & 26 & Impulse & 5.32 & 788.207 & 24 \\
\hline Hearty & 6.192 & 717.862 & 24 & Decision & 7 & 867.448 & 20 \\
\hline Quiet & 5.808 & 810.690 & 23 & Who & 6.64 & 876.724 & 22 \\
\hline Convincing & 6.5 & 981.793 & 25 & What & 5.577 & 881.172 & 17 \\
\hline Touching & 6.154 & 806.379 & 25 & Speak & 6.115 & 750.379 & 25 \\
\hline Statement & 5.846 & 867.690 & 21 & Write & 6 & 814.517 & 23 \\
\hline Concept & 6.192 & 948.655 & 24 & Uncritical & 5.769 & 1186.862 & 14 \\
\hline Analyze & 6.115 & 893.655 & 21 & Critical & 5.56 & 904.483 & 11 \\
\hline Sympathize & 6.538 & 821.931 & 25 & Punctual & 6.308 & 833.345 & 23 \\
\hline Systematic & 6.077 & 904.586 & 21 & Leisurely & 5.692 & 747.000 & 26 \\
\hline Spontaneous & 6.077 & 770.414 & 25 & Concrete & 6.269 & 1131.966 & 22 \\
\hline Justice & 6.923 & 749.621 & 25 & Abstract & 5.692 & 1053.034 & 18 \\
\hline Mercy & 5.923 & 863.517 & 22 & Changing & 5.538 & 929.655 & 24 \\
\hline Reserved & 5.154 & 927.448 & 17 & Permanent & 5.885 & 815.103 & 21 \\
\hline Talkative & 5.962 & 831.862 & 24 & Wary & 4.346 & 1145.241 & 11 \\
\hline Compassion & 6.885 & 668.310 & 26 & Trustful & 7.115 & 711.483 & 27 \\
\hline Foresight & 6.423 & 929.379 & 23 & Build & 6.346 & 876.448 & 17 \\
\hline Systematic & 6.154 & 948.862 & 21 & Invent & 6.885 & 889.069 & 25 \\
\hline Casual & 6.577 & 804.276 & 28 & Orderly & 6.308 & 880.552 & 21 \\
\hline Calm & 6.385 & 622.103 & 27 & Easygoing & 6.885 & 862.586 & 25 \\
\hline Lively & 6.577 & 746.724 & 27 & Foundation & 6.692 & 991.793 & 25 \\
\hline Benefits & 6.577 & 765.276 & 25 & Spire & 5.769 & 1081.586 & 18 \\
\hline Blessings & 6.385 & 742.966 & 27 & Quick & 5.962 & 944.000 & 23 \\
\hline Theory & 5.692 & 965.069 & 21 & Careful & 6.885 & 751.448 & 25 \\
\hline Certainty & 7 & 916.000 & 24 & Theory & 5.654 & 955.655 & 20 \\
\hline Determined & 6.654 & 857.655 & 25 & Experience & 7.192 & 798.759 & 27 \\
\hline Devoted & 6.577 & 877.966 & 26 & Sociable & 7.154 & 797.793 & 23 \\
\hline Literal & 6.192 & 883.690 & 23 & Detached & 4.038 & 835.931 & 8 \\
\hline Figurative & 6.038 & 1118.276 & 19 & Sign & 5.96 & 799.241 & 25 \\
\hline Firm-Minded & 5.885 & 1213.655 & 18 & Symbol & 5.96 & 833.345 & 27 \\
\hline Warm-Hearted & 7.077 & 738.793 & 27 & Party & 6.154 & 687.897 & 26 \\
\hline Imaginative & 6.846 & 861.448 & 26 & Theater & 6.346 & 857.793 & 22 \\
\hline Matter-Of-Fact & 5.692 & 1151.828 & 19 & Accept & 6.423 & 780.138 & 27 \\
\hline Peacemaker & 6.962 & 814.034 & 28 & Change & 6.192 & 842.655 & 18 \\
\hline Judge & 5.846 & 770.586 & 15 & Agree & 6.077 & 719.448 & 28 \\
\hline Make & 5.96 & 920.000 & 25 & Discuss & 6.885 & 893.690 & 20 \\
\hline Create & 6.68 & 693.414 & 28 & Know $\mathrm{n}$ & 7.115 & 735.241 & 23 \\
\hline Soft & 6.2 & 673.345 & 24 & Unknow n & 5.308 & 1069.483 & 9 \\
\hline
\end{tabular}

\section{DISCUSSION}

In this study stimulus words that had higher social desirability values were associated with faster response times. This relationship between social desirability and affect suggests that 
affective judgments are associated with social desirability judgments in that people tend to like things consistent with their internalized schemas of what is socially desirable. Our results are thus consistent with the density hypothesis that positive evaluative information is perceived faster than negative evaluations because there are more positive evaluations in memory [13].

The existence of a general evaluative context seems adequate to explain the findings of the current study. People are presumed to have a general resting baseline of affect which can be further increased or decreased by external pressures. This internal state of affect activation influences future evaluations of a variety of stimuli, including self-descriptive adjectives, and very likely, self-report descriptive statements.

Another factor in this study is that the stimulus words themselves had a positive bias. The lowest social desirability score for any of the words used here was 4, and the highest was 7.2 on a scale of 1 to 9. Affect responses were highly skewed towards the positive, and during debriefing many of the participants asked questions to the effect of "were they (the stimuli) all supposed to be positive?" Presumably this is because the items in the MBTI generate neutral to moderately positive affect because people are asked to judge which of them applies to themselves, and words which generate strong negative affect would be problematic for this purpose. Thus, social desirability and affect judgments may be correlated because the evaluative context for both conditions produced mildly positive affect, which further skewed evaluations for words selected to be positive. Positive words were evaluated faster because positive evaluation is congruent with the evaluative context, and because people tend to attend to negative words for longer. A study in which adjectives were selected to have a full range of desirability values from highly negative to highly positive would be preferable.

Another possible interpretation concerns weaknesses in the current study, which should be addressed in future studies. The validity of assessing affective response by asking people whether they feel a stimulus is good or bad may be questionable. Future research may address this flaw by assessing affect through the affective priming paradigm [14]. A study in which people are asked to make social desirability judgments in a situation with a similar negative evaluative context would help to evaluate the argument that affect and social desirability are related in that they are both strongly influenced by evaluative context.

The findings of the current study are important in that they support the idea that the affect generated by test items may be associated with responding in a socially desirable manner. If social desirability is further shown to be modified by evaluative context in the same ways as affect, this is relevant to work in the areas of stereotypes and social biases in addition to personality assessment.

\section{References}

Slovic, P., Finucane, M., Peters, E., \& MacGregor, D. G. (2002). The affect heuristic. In T. Gilevich, D. Griffin, \& D. Kahneman (Eds.). Heuristics \& biases: The psychology of intuitive judgment (pp. 397-420). Cambridge: Cambridge University Press.

Cacioppo, J. T, Berntson, G. B., \& Gardner, W. L. (1999). The affect system has parallel and integrative processing components: Form follows function. Journal of Personality and Social Psychology, 76, 839-855

Saucier, G. (2008). Measures of the personality factors found recurrently in human lexicons. In G. J. Boyle, G. Matthews, \& D. H. Saklofske (Eds.). Sage handbook of personality theory and assessment. Vol. 2. Personality measurement and testing (pp. 29-54). Los Angeles: Sage.

Wiggins, N. (1966). Individual viewpoints of social desirability. Psychological Bulletin, 66, 68-77. 
Griffith, R. L. \& Peterson, M. H. (2008). The failure of social desirability measures to capture applicant faking behavior. Industrial and Organizational Psychology: Perspectives on Science and Practice, 1, 308-311.

Saucier, G. (2009). Semantic and linguistic aspects of personality. In P. J. Corr \& G. Matthews (eds.). Cambridge handbook of personality psychology (pp.379-399). Cambridge: Cambridge University Press.

Paulhus, D. L. (1991). Enhancement and denial in socially desirable responding. Journal of Personality and Social Psychology, 60, 307-317.

Holden, R. R. (1995). Response latency detection of fakers on personnel tests. Canadian Journal of Behavioural Science, 27, 343-355

Stenberg, G., \& Wiking, S., Dahl, M. (1998). Judging words at face value: Interference in a word processing task reveals automatic processing of affective facial expressions. Cognition and Emotion, 12, 755-782.

Leppänen, J. M., \& Hietanen, J. K., (2003). Affect and face perception: Odors modulate the recognition advantage of happy faces. Emotion, 3, 315-326.

Myers, I. B. \& Briggs, K. C. (1977). The Myers-Briggs Type Indicator, Form G. Palo Alto, CA: Consulting Psychologists Press.

Helmes, E., Harris, J., \& Fraboni, M. (2012). Item format and social desirability: Implications for interpretation of the Myers-Briggs Type Indicator. Psychology Research, 2, 361-368.

Unkelbach, C., Fiedler, K., Bayer, M., Stegmüller, M., \& Danner, D. (2008). Why positive information is processed faster: The density hypothesis. Journal of Personality and Social Psychology, 95, 36-49.

Duckworth, K. L, Bargh, J. A., Garcia, M., \& Chaiken, S. (2002). The automatic evaluation of novel stimuli. Psychological Science, 13, 513-519. 